\section{Trust in Financial Markets: the Role of the Human Element}

\author{
Raquel M. Gaspar1 \\ ${ }^{1}$ Cemapre/REM, ISEG, Universidade de Lisboa, Portugal \\ Paulo Lopes Henriques ${ }^{2}$ \\ ${ }^{2}$ Advance/CSG, ISEG, Universidade de Lisboa, Portugal
}

Ana Rita Corrente ${ }^{3}$

${ }^{3}$ ISEG, Universidade de Lisboa, Portugal
Recebimento:

07/25/2019

Aprovação:

03/10/2020

Editor responsável:

Prof. Dr. Joelson de Oliveira Sampaio

Avaliado pelo sistema:

Double Blind Review

\begin{abstract}
Purpose - This paper suggests that the human element is key when it comes to investors' trust in financial markets. Ignoring it may jeopardise the effectiveness of the recent regulatory growth. The study takes a demand-based perspective, assuming the relationship between financial advisors and investors is based upon trust, and it analyses the conditions that may lead to the existence (or not) of trust.
\end{abstract}

Design/methodology/approach - Using a fuzzy-set qualitative comparative analysis (fsQCA) of data collected from 366 questionnaires, we are able to test, in a qualitative non-parametric way, the conditional arguments that may lead investors to trust (or not) their financial advisor.

Findings - The results show that trust conditions differ, depending on the degree of investors' participation in financial markets. The way investors with a basic relationship with financial markets perceive the behaviour of their financial advisors is key in establishing (or not) their trust. For investors with a more advanced relationship with the market, trust (or its absence) also depends on investors' characteristics. In particular, their financial literacy plays a morethan-negligible role. The joint analysis of the conditions leading to trust and its absence highlights the robustness of our findings.

Originality/value - By understanding the conditions that establish trust, financial institutions can design strategies to strengthen the level of investors' confidence in their services, improving the relationship between market players, and increasing business. From the supervisory authorities' point of view, the approval of a code of conduct for financial advisors, taking into account our results, can help improve the overall trust in financial markets. To the best of our knowledge, this study is the first to apply Butler's (1991) psychometric scale and the fsQCA methodology to study investors' trust in financial advisors.

Keywords - Banking Regulation, Trust, Financial Literacy, fsQCA, Financial Market

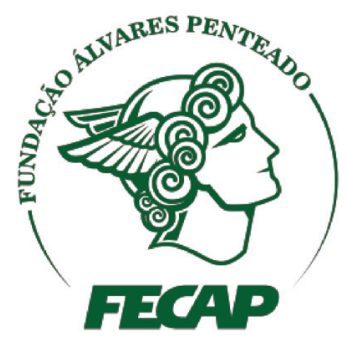

Revista Brasileira de Gestáo de Negócios

DOI:10.7819/rbgn.v22i3.4072 


\section{Introduction}

In the economy, trust can be an important asset (see Fukuyama, 1995; Guiso, Sapienza \& Zingales, 2004; La Porta, Lopez-De-Silanes, Shleifer \& Vishny, 1997). In the context of financial markets, it is fundamental. When trust is lacking, cooperation and financial operations are reduced and investment becomes scarce (Sapienza \& Zingales, 2012). The successive scandals involving players in financial markets (Rezaee, 2005) have contributed significantly to the erosion of trust in these markets (Delis \& Mylonidis, 2015; Sapienza \& Zingales, 2012). To address this situation, regulators have employed an "old recipe" and have started changing regulations, procedures, and practices (Barth, Caprio \& Levine, 2004; Mayer, 2008). Changes such as setting higher minimum values for capital ratios, adopting more restrictive supervisory practices, and attempting to introduce improved and more frequent market information, may lead to a more controlled financial market, but they may not necessarily rebuild investors' trust in it. In fact, these new rules are likely to affect the performance of financial institutions (Chortareas, Garza-Gracia \& Girardone, 2012), indirectly affecting their employees (for example, by reducing head count or cutting remunerations), who are the natural interface between institutions and their clients and, thus, the main drivers of trust. By neglecting the role of financial advisors in rebuilding trust in the sector, regulators are possibly undermining the effectiveness of the recent regulatory growth.

In their research, Sapienza and Zingales (2012) identified a severe drop in the levels of trust in the financial market, and found that the most relevant cause for this fall was related to "managers' greed and poor corporate governance" (pp.128). Even more interestingly, they also reported that "while the majority of the respondents favoured government intervention in the financial markets, $80 \%$ of the pro-intervention majority thought that the way the government intervened made them less, rather than more confident in the market" (pp. 130).

Tapping into the fundaments of trust allows for a quality improvement in the investor/ financial advisor relationship and may help develop more effective regulations in the future. We look at psychometric conditions, as well as financial literacy scores and the investor's type of relationship with financial markets. Our goal is to understand the conditions, or combinations of conditions, that may lead investors to trust (or not) their financial advisors. From a methodological point of view, this study is one of the first in the financial literature to use qualitative comparative analysis (QCA) methods, and the first to use Butler's (1991) psychometric scale to study investors' trust in financial advisors.

The alternative financial applications of QCA, recently identified by Damian and Manea (2019) and Ott, Williams, Saker and Staley (2019), highlight the broad scope of possible future applications of qualitative methods to finance.

The paper is organised as follows. Section 2 provides a brief overview of the current literature about trust in financial markets. Section 3 presents both the survey design and data collection process. Section 4 briefly presents the data analysis method (fsQCA) and Section 5 presents and discusses the results. Section 6 concludes and discusses the limitations of the analysis.

\section{Trust in the Financial System}

Trust and trust relationships have been a topic of research in many disciplines for a number of years. Streams of research on trust can be found in the fields of philosophy, sociology, psychology, management, marketing, ergonomics, humancomputer interaction, industrial psychology and electronic commerce (Paliszkiewicz, 2011). It is, thus, understandable that the literature on trust is quite extensive.

In this section we focus on the much smaller literature stream about trust in the 
financial system and its possible connections to the financial literacy literature. We refer readers interested in the broader scope to the survey studies of Bozic (2017), Guiso, Sapienza and Zingales (2004), Wang and Emurian (2005) and Welter (2012).

Intuitively speaking, trust works in the economy the same way that engine oil works in engines. When trust is present, the cost of a transaction drops, organisations perform better and the whole economy operates in a much more efficient manner (Cruciani \& Rigoni, 2017; Fukuyama, 1995; Guiso, Sapienza \& Zingales, 2009). In the context of the financial sector, particularly with regards to banking services, investors' trust is related to the ability of financial institutions to provide services in an appropriate and competent manner, which encourages the use of banking services (Kim, Shin \& Lee, 2009; Lee \& Chung, 2009). In its most operational form, trust can be considered as the belief that another person or institution is carrying out actions that are beneficial or at least not harmful to other people, regardless of their ability to audit these actions. Accordingly, trust is a key element in market transactions, especially when one of the parties involved in the transaction - the client- often has much lower knowledge about the transaction than the other party (Dearmon \& Grier 2009; Ennew \& Sekhon, 2007; Guiso et al., 2004, 2008; Ferreira, Freitas, Nunes \& Giovannini, 2014; Leislier \& Pinuer, 2016; Mayer, Davis \& Schoorman, 1995).

Studies on the relationship between investors and their financial advisors need to control for financial literacy, given the plethora of works that relate to the two concepts (Cruciaini \& Rigoni, 2017; Gennaioli, Shleifer \& Vishny, 2015; Guiso et al., 2004, 2008, 2009; Rooij, Maarten \& Alessie, 2011). Financial literacy can be defined as being the combination of selfawareness of financial knowledge and financial skills (Xu \& Zia, 2012), the ability to manage personal finances, and the skills required to make appropriate financial decisions (Remund, 2010). These notions are associated with an individual's ability to obtain, understand, and evaluate information that is relevant (Calcagno \& Monticone, 2015), as well as the idea of planning savings, which can lead to achieving higher levels of financial well-being. Individuals with greater financial literacy are likely to better understand how financial markets operate, but also to be more demanding before trusting financial advisors, than individuals who have a low level of financial literacy (Kersting, Marley \& Mellon, 2015; Sarigül, 2014). Consistently, for low levels of financial literacy the relationship between the financial advisor and investor seems to rely mainly on the investor's perception about the advisor's behaviour (Cordell, Smith \& Terry, 2011; Guiso, Sapienza \& Zingales, 2008), whereas in the case of high levels of financial literacy, the same relationship is also based on the investor's knowledge (Calcagno \& Monticone, 2015).

Another aspect that must be taken into account when studying trust is the natural predisposition to trust of each investor. Individuals that have a high predisposition to trust may trust their financial advisors, even in situations of misconduct, and possibly overinvest. For those naturally predisposed not to trust, it may happen that they underinvest. This is in accordance with the evidence that predisposition to trust in advisors affects the likelihood of investing in risky assets (Agnew, Szykman, Utkus \& Young, 2012; Georgarakos \& Pasini, 2011).

Combining both financial literacy and predisposition to trust, it is easy to understand that individuals with low knowledge but a high predisposition to trust are the investors that are most at the mercy of financial advisors. In this case, if an advisor charges high commissions, it is likely that investors will be exploited on the basis of their trust, taking unnecessary risks (Assad, 2015; Simon, Houghton \& Aquino, 2000), and possibly becoming the next "bank victims". 


\section{Survey and Data Collection}

\section{I Questionnaire design}

This study is based upon primary data collected directly from investors, via a questionnaire. Its design relied on the following different pre-existing scales: the well-known trust scale of Butler (1991), the predisposition to trust scale of Yamagishi and Sato (1986), and the financial literacy test proposed by van Rooij, Lusardi and Alessie (2011).

Investors' interactions with financial advisors are classified as being either (i) a basic relationship - for individuals who have only deposit, savings and/or loan accounts, or (ii) an advanced relationship - for individuals who additionally invest in financial markets, either directly, or through products managed by third parties. The two samples are treated separately, to enable us to discern the differences that occur between the two groups.
Besides an initial section dedicated to demographic questions, the core of our questionnaire had a total of 41 questions. The first 26 are psychometric questions and invite the respondent to express their level of agreement or disagreement with a statement, using a 1 to 5 Likert scale, where 1 means strongly disagrees, and 5 means strongly agrees. The remaining 15 questions constitute a financial knowledge test, leading to the attribution of a financial score, between 0 and 15 , to each respondent.

The overall trust condition of Butler (1991) is used to measure the total degree of trust (trust) present in the investor/financial advisor relationship - which is the key variable under analysis.

The remaining variables can be divided between those that are related to investors' characteristics and those that are related to the behaviour of financial advisors (Table 1).

Table 1

\section{Conditions for Trust Analysis}

\begin{tabular}{ll}
\hline Investor Characteristics & Financial Advisor Behaviour \\
\hline Predisposition to trust $=>$ prtrust & Integrity $=>$ integ \\
Financial literacy $=>$ finlit & Availability $=>$ avail \\
Age $=>$ age & Promise fulfilment $=>$ promfull \\
& Competence $=>$ compet \\
\hline
\end{tabular}

\section{I.I Investors' characteristics}

The investors' characteristics considered here as possible conditions are: the predisposition to trust (prtrust), financial literacy (finlit) and age (age).

We expect the financial advisor's behaviour to play a less important role for an individual with a high predisposition to trust. Financial literacy is likely to play a dual role: more financially literate investors are likely to be more demanding with their advisors, but low financial literacy may prevent investors from engaging in more advanced investments. In terms of our demographic variables, only age was revealed to be useful as a condition of trust. Age is probably important as we expect older people to be more experienced in appraising relationships.

\section{I.2 The behaviour of the financial advisor}

Butler (1991) proposes that trust is based on a variety of behavioural properties whose trustworthiness is under scrutiny. Butler's scale has been extensively validated and offers relatively clear categories of behaviour which can be used to engender trust, working with conditions that propagate trust, rather than the dimensions of trust. Also, compared to alternative trust scales, Butler's focuses on the conditions of trust for a specific target, which fits our purpose. 
From the original ten conditions of Butler we selected the four that best relate to the behaviour of financial advisors, namely: integrity (integ), availability (avail), promise fulfilment (promffull), and competence (compet).

This selection is based on the notion of how easy it is for the investor to make a fair dayto-day evaluation about the topics mentioned. Availability, which means being physically present with an open door policy, is an easy condition to monitor. Competence relates to good advice, and is usually perceived based on past performance, leading an investor to trust an advisor who helps him/her with good investments over time. Finally, the conditions of promise fulfilment (keeping true to one's word) and integrity (not lying) are related to the capacity to resist being less than honest when communicating with clients. Financial advisors are often placed in difficult situations where they have to justify some difficult options for their clients (Williamson, 1993). Sometimes these justifications may be more opportunistic than honest. We expect investors to be more likely to trust their advisors when they fully perceive honesty and realism.

The other conditions of Butler (1991) - openness, loyalty, fairness, discreteness, receptivity, and reliability - are not used, as it is harder to apply them directly to the relationship between investors and financial advisors.

It is important to note that we are adapting and using Butler's (1991) conditions outside the original context - namely that of the supervisorsubordinate relationship. Here, the intention is to function "out of the box", helping to understand how investors perceive their financial advisor's behaviour, and its relationship with overall trust.

\subsection{The data collection process and robustness}

Before being made public, the survey was subjected to a pre-test, with 10 people, which enabled us to verify the need to change the written form of seven questions. Once re-formulated, the survey was sent to the respondents not only by email (with a link to the questionnaire), but also by Facebook and LinkedIn, through private messages.

The initial respondents were selected based on the researchers' personal contacts and students attending the corporate sciences master held at ISEG, Universidade de Lisboa. In the message we asked each first receiver to resend the link to their personal database of contacts, thus configuring a snow ball method.

This enabled us to reach a larger number of investors. A total of 399 questionnaires were collected, 21 of which were not included in the analysis because the respondents did not fit the required profile (e.g., they were not 18 years of age or older and/or had no currently active bank account). Subsequently, a further 12 questionnaires were discarded because the respondents had a level of financial literacy that was equal to zero. All in all, only 366 questionnaires were valid for analysis.

Table 2

Investor Demographics

\begin{tabular}{lccc}
\hline Gender & & \multicolumn{2}{c}{ Marital status } \\
\hline Male & $49.50 \%$ & Single & $84.1 \%$ \\
Female & $50.50 \%$ & Married & $15.80 \%$ \\
Age & & No income & Monthly income \\
$\quad 18$ to 25 years old & $51.60 \%$ & Up to $1000 €$ & $47.80 \%$ \\
26 to 35 years old & $30.60 \%$ & More than $1000 €$ & $31.60 \%$ \\
$\quad+$ than 36 years old & $17.60 \%$ & Years at school & $3.0 \%$ \\
Professional status & & 9 years & $23.20 \%$ \\
$\quad$ Student & $20.50 \%$ & 12 years & $49.50 \%$ \\
$\quad$ Working & $75.20 \%$ & 15 years & $23.40 \%$ \\
$\quad$ Unemployed & $3.60 \%$ & 18 years or more & \\
$\quad$ Retired & $0.80 \%$ & & \\
\hline
\end{tabular}


The respondents' profiles are shown in Table 2, which classifies them according to gender and shows the predominance of young, single, employed, and educated clients.

The answers collected from the questionnaires were treated using the SPSS software and the fuzzy-set qualitative comparative analysis (fsQCA) software. In our case the aim was to identify configurations that may lead to either trust or to its absence and our seven conditional variables are: (1) age; (2) personal confidence; (3) availability; (4) competence; (5) integrity; (6) promise fulfilment; and (7) financial literacy. Table 3 presents some descriptive statistics and reports the calibration values for our set of conditions.

Table 3

Descriptive statistics of conditions, calibration values, and Cronbach's alfa $(\alpha)$

\begin{tabular}{|c|c|c|c|c|c|c|c|c|c|}
\hline \multicolumn{10}{|c|}{ Basic relationship } \\
\hline $\mathrm{N}$ & 319 & Female & Male & & & & & & \\
\hline Gender & & $55.8 \%$ & $44.2 \%$ & & & & & & \\
\hline Conditions & & $\begin{array}{c}\text { Trust } \\
(\alpha=0.792)\end{array}$ & age & $\begin{array}{c}\text { prtrust } \\
(\alpha=0.820)\end{array}$ & $\begin{array}{c}\text { avail } \\
(\alpha=0.884)\end{array}$ & $\begin{array}{c}\text { compet } \\
(\alpha=0.815)\end{array}$ & $\begin{array}{c}\text { integ } \\
(\alpha=0.743)\end{array}$ & $\begin{array}{l}\text { promfful } \\
(\alpha=0.781)\end{array}$ & finlit $^{1}$ \\
\hline Mean & & 3.43 & 28 & 3.28 & 3.39 & 3.61 & 3.39 & 3.47 & 6.96 \\
\hline Stdev & & 0.87 & 8.51 & 0.69 & 0.90 & 0.75 & 0.80 & 0.75 & 3.48 \\
\hline Min & & 1 & 18 & 1.33 & 1 & 1 & 1 & 1 & 1 \\
\hline Max & & 5 & 70 & 5 & 5 & 5 & 5 & 5 & 15 \\
\hline \multicolumn{10}{|c|}{ Calibration values at percentile: } \\
\hline 95 & & 5 & 49.15 & 4.19 & 5 & 5 & 4.67 & 5 & 13 \\
\hline 50 & & 3.33 & 25 & 3.33 & 3.33 & 3.5 & 3.33 & 3.25 & 7 \\
\hline 5 & & 2 & 21 & 2 & 1.67 & 2.5 & 2 & 2.46 & 1 \\
\hline \multicolumn{10}{|c|}{ Advanced relationship } \\
\hline $\mathrm{N}$ & 48 & Female & Male & & & & & & \\
\hline Gender & & $16.7 \%$ & $83.3 \%$ & & & & & & \\
\hline Conditions & & $\begin{array}{c}\text { Trust } \\
(\alpha=0.922)\end{array}$ & age & $\begin{array}{c}\text { prtrust } \\
(\alpha=0.905)\end{array}$ & $\begin{array}{c}\text { avail } \\
(\alpha=0.898)\end{array}$ & $\begin{array}{c}\text { compet } \\
(\alpha=0.896)\end{array}$ & $\begin{array}{c}\text { integ } \\
(\alpha=0.893)\end{array}$ & $\begin{array}{l}\text { promfful } \\
(\alpha=0.855)\end{array}$ & finlit $^{1}$ \\
\hline Mean & & 3.60 & 34 & 3.42 & 3.68 & 3.77 & 3.36 & 3.70 & \\
\hline Stdev & & 0.85 & 10.45 & 0.89 & 0.87 & 0.80 & 0.79 & 0.84 & 3.06 \\
\hline Min & & 1.67 & 21 & 1.33 & 1.33 & 1.5 & 1.33 & 1.5 & 3 \\
\hline Max & & 5 & 58 & 5 & 5 & 5 & 5 & 5 & 15 \\
\hline \multicolumn{10}{|c|}{ Calibration values at percentile: } \\
\hline 95 & & 5 & 55 & 4,83 & 5 & 5 & 4.67 & 5 & 14 \\
\hline 50 & & 3.75 & 31 & 3.50 & 4 & 3.75 & 3.33 & 3.75 & 11 \\
\hline 5 & & 2.33 & 22.3 & 1.88 & 2 & 2.5 & 2.11 & 2.33 & 4.7 \\
\hline
\end{tabular}

Legend: age $=$ age of the respondent; prtrust $=$ predisposition to trust; avail $=$ availability; compet $=$ competence; integ $=$ integrity; Trust $=$ overall trust promfful = promise fulfilment; finlit $=$ financial literacy. $1-$ As the finlit condition is a test score, its reliability has not been computed.

The reliability of each of our psychometric conditions in each group is attested by the high Cronbach's alfa values in Table 3. A reliability analysis was also carried out for the whole sample, i.e. without splitting the sample into the two groups, and this also showed high reliability values (Trust ( $\alpha=0.932)$, promffull $(\alpha=0.803)$, integrity ( $\alpha=0.848)$, compt $(\alpha=0.897)$, aval $(\alpha=0.891)$ 
and predisposition to trust $(\alpha=0.839))$. As the financial literacy condition is not a psychometric variable, but rather a test score, its reliability was not computed.

In addition, following the advice of Podsakoff, MacKenzie, Lee and Podsakoff (2003), we controlled for the common method variance, both during the preparation of the questionnaire and after collecting the data. The measures taken were the following: a) the order of the questions was counterbalanced and some of them were formulated in the negative; b) total anonymity was guaranteed and all information that could serve to back-track to the respondent was removed; and c) the Harman's single-factor test and common latent factor technique were applied to the data collected. The results suggest the absence of bias.

\section{Method}

Qualitative comparative analysis (QCA) applies rules of logical inference to determine which descriptive inferences or implications the data support. Each "case", called configuration here, is understood to be a combination of factors or conditions (Ragin, 2000). A configuration is "a specific combination of conditions that produces a particular result of interest" (Rihoux \& Ragin, 2008). According to Rihoux (2009), QCA can be a useful tool for several purposes: to summarise data and identify patterns, to explore similarities and differences between configurations, to verify the consistency of data, and to test new ideas and develop new hypotheses or theories. Although QCA has some limitations, it has a number of strengths, such as the ability to carry out a qualitative impact assessment and the identification of multiple paths to achieve the outcome (Garcia-Álvarez-Coque, Mas-Verdú \& Roig-Tierno 2019; Kraus, Ribeiro \& Schüßler 2018), without being subject to the typical constraints of regression-based techniques (both computationally, due to collinearity and power issues, and in terms of interpretation) (Fiss, 2007, 2011; Rihoux \& Ragin, 2008; Woodside, Nagy \& Megehee 2018)
In the data processing, we looked for explicit connections, rather than trying to establish correlations - as most traditional statistical approaches do. In particular, we did not wish to restrict ourselves to one solution, as different multiple configurations may lead to the same outcome, and we wanted to identify the configurations for trust and its absence separately (Meyer, Tsui \& Hinings, 1993). These two properties, known as equifinality and asymmetric causality, are specific to QCA, making it a particularly good fit for our analysis. The use of QCA simplifies complex structures (Basedau \& Richter, 2014) and consequently enables a greater understanding of the phenomenon under study.

The results of the present study are analysed according to the fuzzy-set theory (fsQCA). The fsQCA methodology is grounded in Boolean algebra - the algebra of logic and sets - and it mimics "human thinking, particularly in the domains of pattern recognition, communication of information, and abstraction" (Zadeh, 1965, p. 339). Like human process information, the fsQCA methodology can be used to make configurational classifications and to carry out judgments based on the simultaneous consideration of multiple interdependent factors. Accordingly, we find it to be particularly appropriate for our analysis. On the analytical front, fsQCA provides a unique middle ground between qualitative and quantitative methods. Further details about the connection of fsQCA to set theory can be seen in the work of Smithson and Verkuilen (2006). Further technical details related to the exact pattern recognition method are outside the scope of this study - we refer the reader to Ragin (2009). The exact method implementation routine we used - fsQCA 2.5 - is available at www.fsqca.com. Fuzzy sets "welcome" the presence of a certain degree of ambiguity, which is natural in social science constructs. It allows the use of interval scale variables - which first require a calibration for categories or fuzzy conditions. This calibration consists of assigning the variables a value between 0.0 and 1.0, depending on their 
degree of adhesion to the outcome (Woodside $\&$ Zhang, 2012). The value between 0 and 1 reflects the degree of membership in each class (Zadeh, $1965)$, and it is thus consistent with the principle of fuzzy information granulation and fuzzy logic, which is central to human cognition and decision making (Zadeh, 1983, 1997).

\section{Results and Discussion}

Using the fsQCA methodology, we tested all the possible configurations of our set of seven conditions - age (age), predisposition to trust (prtrust), financial literacy (finlit), integrity (integ), availability (avail), competence (compet), and promise fulfilment (promfull) - for the two types of investor relationships, and we analysed both the presence and absence of trust.

Our observations are pairs of outcome/ configurations of conditions, and two different approaches can be taken. On the one hand, one can try to identify conditions shared by configurations with the same outcome. In this case, we looked into a particular outcome realization - trust or absence of trust - and checked which conditions are common in the associated configurations and could be understood as causal. This is useful to obtain the necessary conditions. On the other hand, one can examine observations with the same configurations (or subset of configurations) to see if they share the same outcome. This is suitable for the assessment of sufficient conditions.

Next, we present and discuss the results in terms of necessary and sufficient conditions of Trust and $\sim$ Trust (with the symbol denoting absence), for both basic and advanced relationships between investors and financial advisors.

\subsection{Necessary conditions}

A necessary condition is one which appears to enable the outcome (Mannewitz, 2011). A condition or configuration is considered to be "necessary", or "almost always necessary", if its consistency score (percentage of observations showing that condition or configuration and presenting the outcome under analysis) is high. Some authors consider configurations with consistency scores above 0.8 to be interpretable as necessary (Ragin, 2000; Schneider, SchulzeBentrop \& Paunescu, 2010), but more conservative ones recommend they exceed the limit of 0.9 (Schneider \& Wagemann, 2012). Here we take the more conservative, thus more robust, approach. Tables 4 and 5 respectively present the results on the necessary conditions for the Trust outcome (Table 4) and its absence ( Trust) (Table 5).

Another relevant statistic is coverage, which attests the empirical relevance of the results and indicates the share of the outcome covered by each condition or configuration.

According to Table 4, the conditions of availability and integrity are necessary for the basic-type investors to trust, whereas for the advanced-type investors the necessary conditions are availability, promise fulfilment, and financial literacy, adding a more personal characteristic of the investor to achieve trust. These results follow those of the literature, in that when the relationship is basic, the necessary conditions are clearly related to the behaviour of the advisor and based on successive experiences over time, in which the investor demonstrates a reasonably passive action, with low participation (Cordell, Smith \& Terry, 2011). 
Table 4

Necessary Conditions Analysis (outcome: Trust)

\begin{tabular}{|c|c|c|c|c|}
\hline \multirow[b]{2}{*}{ Conditions } & \multicolumn{2}{|c|}{ Basic Relationship } & \multicolumn{2}{|c|}{ Advanced Relationship } \\
\hline & Consistency & Coverage & Consistency & Coverage \\
\hline$\sim$ prtrust & 0.543 & 0.600 & 0.374 & 0.511 \\
\hline prtrust & 0.768 & 0.751 & 0.843 & 0.814 \\
\hline -avail & 0.487 & 0.535 & 0.356 & 0.529 \\
\hline avail & 0.921 & 0.903 & 0.957 & 0.873 \\
\hline -compet & 0.475 & 0.498 & 0.403 & 0.529 \\
\hline compet & 0.870 & 0.894 & 0.881 & 0.875 \\
\hline -integ & 0.477 & 0.518 & 0.477 & 0.538 \\
\hline integ & 0.922 & 0.914 & 0.839 & 0.951 \\
\hline -promfful & 0.481 & 0.507 & 0.358 & 0.507 \\
\hline promfful & 0.891 & 0.909 & 0.915 & 0.862 \\
\hline$\sim$ finlit & 0.585 & 0.665 & 0.233 & 0.662 \\
\hline finlit & 0.718 & 0.685 & 0.951 & 0.672 \\
\hline -age & 0.726 & 0.695 & 0.432 & 0.709 \\
\hline age & 0.619 & 0.700 & 0.809 & 0.698 \\
\hline
\end{tabular}

Legend: age $=$ age of the respondent; prtrust $=$ predisposition to trust; avail = availability; compet = competence; integ $=$ integrity; Trust $=$ overall trust promfful $=$ promise fulfillment; finlit $=$ financial literacy; $(\sim)$ absence of the condition.

On the other hand, investor characteristics were shown to be necessary for advanced relationships, in accordance with the expectation that these investors participate more actively in the investment process (Kersting, Marley \& Mellon, 2015).
Concentrating our attention on the absence of an outcome ( $\sim$ Trust) (Table 5 ) for the basic relationship, the necessary conditions reflect the absence of good behaviour of the financial advisor captured by the absence of integrity or promise fulfilment. For the advanced relationship the necessary condition is the absence of integrity. 
Table 5

Necessary Conditions Analysis (absence of outcome: - Trust)

\begin{tabular}{lcccc}
\hline & \multicolumn{2}{c}{ Basic Relationship } & \multicolumn{2}{c}{ Advanced Relationship } \\
\hline Conditions & Consistency & Coverage & Consistency & Coverage \\
\hline -prtrust & 0.725 & 0.744 & 0.750 & 0.786 \\
prtrust & 0.610 & 0.554 & 0.534 & 0.396 \\
- avail & 0.894 & 0.913 & 0.819 & 0.936 \\
avail & 0.545 & 0.497 & 0.588 & 0.412 \\
- compet & 0.889 & 0.864 & 0.837 & 0.844 \\
compet & 0.483 & 0.461 & 0.533 & 0.407 \\
-integ & $\mathbf{0 . 9 0 7}$ & 0.916 & $\mathbf{0 . 9 4 4}$ & 0.818 \\
integ & 0.523 & 0.481 & 0.467 & 0.406 \\
-promfful & $\mathbf{0 . 9 0 4}$ & 0.885 & 0.809 & 0.880 \\
promfful & 0.497 & 0.471 & 0.547 & 0.395 \\
-finlit & 0.644 & 0.680 & 0.396 & 0.862 \\
finlit & 0.682 & 0.604 & 0.844 & 0.458 \\
-age & 0.714 & 0.635 & 0.545 & $0 / .687$ \\
age & 0.657 & 0.690 & 0.769 & 0.509 \\
\hline \hline
\end{tabular}

Legend: $\mathbf{a g e}=$ age of the respondent; prtrust $=$ predisposition to trust $;$ avail $=$ availability $;$ compet $=$ competence; integ $=$ integrity; Trust $=$ overall trust promfful $=$ promise fulfilment; finlit $=$ financial literacy; $(\sim)$ absence of the condition.

Note that necessary conditions leading to the absence of trust depend heavily and mostly on the perception investors have about the behaviour of the financial advisor, independently of the level of the relationship. Another interesting observation is that despite the fact that financial literacy (or its absence) turns out not to be a necessary condition, its existence presents much higher consistency scores for advanced relationships, possibly indicating that in order for advanced investors to trust, knowledge about the way that financial markets operate may still be important.

Our results follow previous findings in the literature, namely that financial literacy acts in practice as a condition for generating trust whereas the absence of proper behaviour on the part of the financial advisor leads to the absence of trust (Flores \& Vieira, 2014; Glaser \& Walter, 2014; Sapienza \& Zingales, 2012). From a different perspective, the fact that financial literacy is almost necessary for advanced investors to trust financial advisors is in line with the idea that in almost all cases only financially literate investors engage in advanced relationships.

For all conditions meeting the consistency threshold, coverage is high, highlighting the statistical relevance of the results discussed.

\section{$5 \cdot 3$ Sufficient conditions}

Solutions of sufficient conditions allow for the identification of different combinations of configurations that are jointly likely to lead to the outcome (Baptist \& Befani, 2015; Greckhamer, Misangyi, Elms \& Lacey, 2008). Note that each configuration is a combination of conditions.

The focus now is on the outcome and there are different types of solutions, depending on how the remaining observations (those not in accordance with the pair outcome/ considered configurations) are handled. Using the recommendations of Schneider and Wagemann (2010), this study presents the results for the socalled intermediate solution (which uses only the remainders that survive counterfactual analysis) and parsimonious solution (which permits the use 
of any remainder that yields simpler recipes). Tables 6 and 7 report those solutions for both the Trust and the $\sim$ Trust outcomes.

A solution should be understood as the union of configurations. For instance, a solution presenting three configurations leading to the outcome should be interpreted as: "configuration 1 OR configuration 2 OR configuration 3, are likely to lead to the outcome". Individually, each of the configurations may add a different contribution to the solution so one needs to discuss the statistical relevance of solutions and of their configuration perse.

As before, sufficient solutions must meet minimum criteria, both in terms of consistency and coverage. Coverage measures support the researcher in determining which percentage of the outcome is covered through a solution or configuration. We can differentiate between solution coverage (share of the outcome jointly covered by the solution, i.e. by the sum of the proposed configurations), raw coverage (share of the outcome explained by a particular configuration), and unique coverage (share of the outcome exclusively explained by a particular configuration). Similarly, we can analyse both the solution consistency (percentage of observations in accordance with any of the proposed configurations) and configuration consistency (share of observations in accordance with a particular configuration).

The typical limits are that for the overall solution the coverage score should be greater than 0.25 (guaranteeing empirical importance of the solutions offered) and consistency should be 0.75 or more (Ragin, 2009; Woodside, 2013). For each configuration, raw coverage and consistency should be higher than 0.25 and 0.85 , respectively (Rihoux \& Ragin 2008). In what follows all solutions meet the required consistency and coverage criteria. As regards to the possible configurations within each solution, we opted to interpret only the configurations that meet the required raw coverage and consistency criteria, as the others are not statistically relevant.
Table 6 presents the intermediate and parsimonious solutions for trust, for both basic and advanced relationships. For a better understanding of each solution we use the notation "*” for and together with “+” for OR.

The intermediate solution for trust for the basic relationship investors results from a combination of five configurations,

\section{integ*avail $+\sim$ finlit*integ* ${ }^{*}$-age + $\sim$ finlit* $^{*}$ avail ${ }^{*} \sim$ prtrust + integ ${ }^{*} \sim$ prtrust*age + avail $^{*} \sim$ prtrust* ${ }^{*}$ age,}

whereas the parsimonious solution results mainly from two conditions,

\section{integ + avail.}

For the advanced relationship, the intermediate solution can be described as a combination of two relevant configurations,

\section{finlit*avail*age + finlit*integ*avail*prtrust,}

while the parsimonious solution points to only one relevant condition,

avail.

Interpreting the intermediate solutions, it becomes apparent from the dataset related to the basic relationship that availability (avail) and integrity (integ) conditions are very important for achieving trust, as they are present in all the configurations. It is also important to emphasise that trust may occur even in the absence of predisposition to trust ( $\sim$ prtrust), provided that availability (avail) or integrity (integ) are included in the same configuration, as these show up in three out of five configurations. However, the absence of predisposition to trust $(\sim$ prtrust) does not appear in the configurations of the intermediate solution for the advanced relationship. This may be linked to the tendency 
that investors with a low predisposition to trust have to engage in a low level of participation, i.e. a basic relationship with the market (Flores \& Vieira, 2014; Glaser \& Walter, 2014).

Table 6

\section{Intermediate and Parsimonious Solutions for the Trust Outcome}

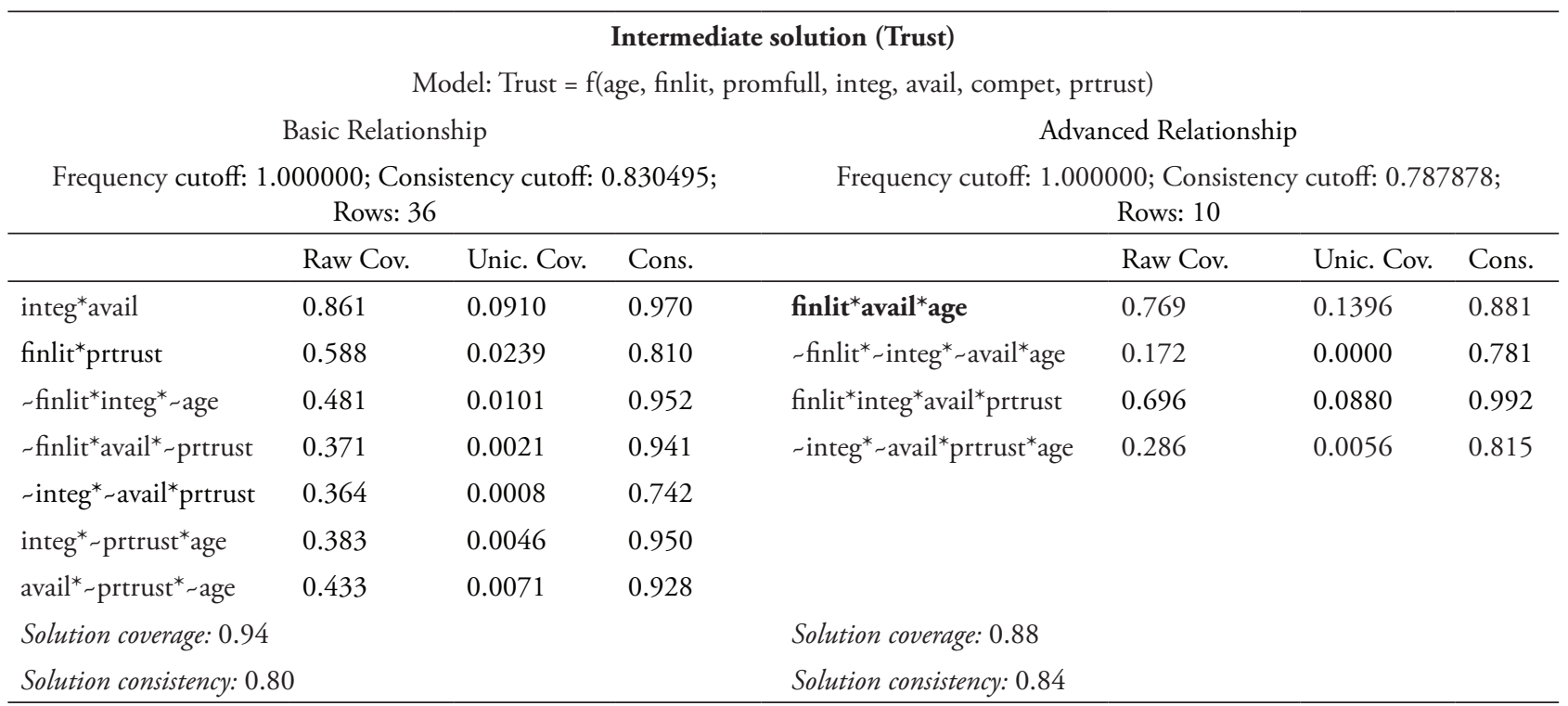

\section{Parsimonious Solution (Trust)}

Model: Trust $=\mathrm{f}($ age, finlit, promfull, integ, avail, compet, prtrust $)$

Basic Relationship

Frequency cutoff: 1.000000; Consistency cutoff: 0.830495; Rows: 27

Advanced Relationship

Frequency cutoff: 1.000000; Consistency cutoff: 0.787878; Rows: 11

\begin{tabular}{|c|c|c|c|c|c|c|c|}
\hline & Raw Cov. & Unic. Cov. & Cons. & & Raw Cov. & Unic. Cov. & Cons. \\
\hline Prtrust & 0.768 & 0.0085 & 0.751 & prtrust & 0.843 & 0.0226 & 0.814 \\
\hline Avail & 0.921 & 0.0274 & 0.903 & avail & 0.957 & 0.1340 & 0.873 \\
\hline Integ & 0.922 & 0.0253 & 0.914 & age*_finlit & 0.220 & -0.0000 & 0.797 \\
\hline \multicolumn{4}{|c|}{ Solution coverage: 0.99} & \multicolumn{4}{|l|}{ Solution coverage: 0.99} \\
\hline \multicolumn{4}{|c|}{ Solution consistency: 0.75} & \multicolumn{4}{|l|}{ Solution consistency: 0.77} \\
\hline
\end{tabular}

Legend: age = age of the respondent; prtrust = predisposition to trust; avail $=$ availability; compet $=$ competence; integ $=$ integrity; Trust = overall trust; promfful = promise fulfilment; finlit $=$ financial literacy; $(\sim)$ absence of the condition; Raw Cov. = raw coverage; Unic. Cov. = unique coverage; Cons. = consistency

As one would expected, in the configurations of the basic relationship the absence of financial literacy ( $\sim$ finlit) appears, while when looking at the advanced relationship there is the existence of financial literacy (finlit), which corroborates findings that investors with higher levels of financial literacy tend to operate at higher levels of relationship, and that they use this literacy to establish the levels of their trust in financial advisors (Calcagno \& Monticone, 2015). On the other hand, low levels of financial literacy may leave the investor no other option than to trust their advisor. 
Besides financial literacy, availability (avail) shows up in all relevant configurations of the advanced relationship, combined with age (age) and/or predisposition to trust (prtrust). Once again, for advanced relationships, besides conditions related to the financial advisor, we also find the investor-related conditions financial literacy, age and predisposition to trust. This indicates that, at an advanced level of relationship, the investor uses their knowledge about the way the market operates (finlit) and experience (age) to make decisions and build up trust, which corroborates the ideas of Kersting, Marley and Mellon (2015) and Sarigül (2014). The predisposition to trust (prtrust) condition appears to be a sufficient condition when associated with integrity (integ) and financial literacy (finlit), which indicates that it acts as a reinforcement to the previously-mentioned conditions. This result is in line with the suggestions advocated by Yamagishi and Sato (1986).

One of the unexpected results is that the competence (compet) condition (the ability of the financial advisor to offer good advice as perceived by investors) did not appear in the intermediate solutions, not even in the advanced relationship dataset. Although it is not clear why this is exactly, we can imagine a possible explanation. It could be that investors perceive that their financial advisor is becoming increasingly conditioned by regulations and procedures, which affect the type of advice they can give, leaving no room for personal skills to smooth the relationship between the investor and the financial advisor.

The parsimonious solutions, for the basic relationship, identify as alternative conditions integrity (integ) or availability (avail). This shows that at this level, trust is conditioned by the behaviour of the financial advisor and it is particularly important that investors perceive the advisor as being available to clarify and support them and that they resist the use of incorrect behaviour to justify complex or difficult situations. For the advanced relationship, availability (avail) is the only relevant condition of the parsimonious solution.

The above results indicate that trust conditions are different for the different relationships with the financial market, although availability is a common condition to both relationships and across solutions. 
Table 7

Intermediate and Parsimonious Solutions for the $\sim$ Trust Outcome

\begin{tabular}{|c|c|c|c|c|c|c|c|}
\hline \multicolumn{8}{|c|}{ Intermediate solution $(\sim$ Trust $)$} \\
\hline \multicolumn{8}{|c|}{ Model: $\sim$ Trust $=$ f(age, finlit, promffull, integ, compet, avail, prtrust) } \\
\hline \multicolumn{4}{|c|}{ Basic Relationship } & \multicolumn{4}{|c|}{ Advanced Relationship } \\
\hline \multicolumn{4}{|c|}{$\begin{array}{c}\text { Frequency cutoff: } 1.000000 \text {; Consistency cutoff: } 0.928902 \text {; } \\
\text { Rows: } 40\end{array}$} & \multicolumn{4}{|c|}{$\begin{array}{c}\text { Frequency cutoff: } 1.000000 \text {; Consistency cutoff: } 0.774732 \text {; } \\
\text { Rows: } 14\end{array}$} \\
\hline & Raw Cov. & Unic. Cov. & Cons. & & Raw Cov. & Unic. Cov. & Cons. \\
\hline -integ* -avail & 0.829 & 0.0719 & 0.977 & $\sim$ integ $^{*} \sim$ avail $^{*} \sim$ prtrust & 0.630 & 0.1611 & 0.980 \\
\hline$\sim$ finlit ${ }^{*}$-integ ${ }^{*} \sim$ prtrust & 0.491 & 0.0025 & 0.953 & -integ* -avail*age & 0.616 & 0.0151 & 0.964 \\
\hline finlit*-integ*prtrust & 0.459 & 0.0228 & 0.931 & finlit*-integ*age & 0.686 & 0.0455 & 0.801 \\
\hline -integ ${ }^{*}$-prtrust ${ }^{*}$-age & 0.530 & 0.0093 & 0.945 & finlit*avail ${ }^{*}$-prtrust*age & 0.402 & 0.0096 & 0.774 \\
\hline -finlit*_avail*_age & 0.514 & 0.0011 & 0.944 & & & & \\
\hline -finlit*-avail ${ }^{*}$-prtrust & 0.500 & 0.0000 & 0.964 & & & & \\
\hline -avail*prtrust* _age & 0.456 & 0.0000 & 0.921 & & & & \\
\hline -avail ${ }^{*} \sim$ prtrust*age & 0.464 & 0.0022 & 0.968 & & & & \\
\hline finlit* ${ }^{*}$ avail*prtrust & 0.458 & 0.0060 & 0.925 & & & & \\
\hline Solution coverage: 0.93 & & & & Solution coverage: 0.90 & & & \\
\hline Solution consistency: 0.89 & & & & Solution consistency: 0.79 & & & \\
\hline
\end{tabular}

\section{Parsimonious solution ( $\sim$ Trust)}

Model: $\sim$ Trust $=\mathrm{f}($ age, finlit, promffull, integ, compet, avail, prtrust $)$

Basic Relationship

Frequency cutoff: 1.000000; Consistency cutoff: 0.928902; Rows: 27

\begin{tabular}{llllllll} 
& \multicolumn{1}{c}{ Rows: 27} & \multicolumn{3}{c}{ Rows: 11} \\
\hline & Raw Cov. & Unic. Cov. & Cons. & & Raw Cov. & Unic. Cov. & Cons. \\
\hline -integ & 0.907 & 0.0777 & 0.916 & - integ & 0.944 & 0.2246 & 0.818 \\
-avail & 0.894 & 0.0641 & 0.913 & - prtrust & 0.750 & 0.0303 & 0.786 \\
Solution coverage: 0.97 & & & & Solution coverage: 0.97 & & & \\
Solution consistency: 0.87 & & & & Solution consistency: 0.75 & & \\
\hline
\end{tabular}

Legend: age $=$ age of the respondent; prtrust $=$ predisposition to trust; avail $=$ availability; compet $=$ competence; integ $=$ integrity; promfful $=$ promise fulfilment; finlit $=$ financial literacy; $(\sim)$ absence of the condition; Raw Cov. = raw coverage; Unic. Cov. = unique coverage; Cons. = consistency

Table 7 presents the intermediate and parsimonious solutions for the outcome absence of trust ( $\sim$ Trust). This is done to enrich the research, in the sense that by using the same information, it is possible to study the two faces of the same coin and to evaluate the robustness of the conclusions reached. The results in Table 7

Advanced Relationship

Frequency cutoff: 1.000000; Consistency cutoff: 0.774732; Rows: 11 
whereas the parsimonious solution results show two conditions

-integ + - avail.

For the advanced relationship, the intermediate solution presents only two configurations that meet the consistency criteria,

\section{$\sim_{\text {integ }}^{*} \sim$ avail $^{*} \sim$ prtrust $+\sim$ integ ${ }^{*} \sim$ avail*age,}

but in the parsimonious solution, no condition meets the required limit.

Note that, in general, the configurations of conditions for the absence of trust outcome are mainly the opposite to those identified for the trust outcome - which indicates the robustness of our study.

It is notable from the parsimonious solution for the basic relationship data that in order for the absence of trust to occur, it is sufficient for the investor to perceive the absence of integrity ( integ) or a lack of availability ( - avail).

A final comment follows on the role of age in our intermediate results across outcomes and relationships. It is important to highlight the age condition (which in this study means older, with - age meaning younger) does not behave like the other conditions. Both age and - age appear in some configurations leading to both trust (Trust) and the absence of trust ( $\sim$ Trust). This is, nonetheless, in line with the literature that claims that older, more experienced people detect trust or distrust (Castle et al. 2012; Lusardi \& Mitchell, 2007).

Besides analysing the solutions and their configurations, the (individual) conditions contained in the configurations of the two types of solutions can also be analysed. Comparing the intermediate and parsimonious solutions allows us to identify the so-called core conditions (those that are present in both solutions) and the peripheral conditions (those that do not appear in both solutions). Table 8 summarises the results of Tables 6 and 7 using a different notation (e.g. Nieto-Alemán, Garcia-Alvarez-Coque, RoigTierno \& Mas-Verdú, 2019; Nieto-Alemán, RoigTierno, Mas-Verdú \& García-Álvarez-Coque, 2018), allowing configurations for both advanced and basic relationships to be compared regarding both the trust outcome (Trust) and its absence ( $\sim$ Trust). This enables a better understanding of the differences in the configuration of the conditions that leads to the outcomes. By examining Table 8 , we can summarize our key results as follows: a) core conditions are related to the behaviour of the financial advisor, independently of the scenario, or the outcome, which reveals their importance; b) the conditions related to the investor are peripheral, independently of the scenario or the outcome; and c) in spite of being peripheral, financial literacy (finlit) contributes to building trustworthy relations between advanced investors and financial advisors. 
Table 8

Configurations Comparison (consistency > 0.9)

\begin{tabular}{|c|c|c|c|c|c|c|c|c|c|c|}
\hline \multirow{3}{*}{$\begin{array}{l}\text { Configurations } \\
\text { Trust Basic Relationship } \\
\text { integ*avail }\end{array}$} & \multicolumn{6}{|c|}{ Client-related conditions } & \multicolumn{4}{|c|}{$\begin{array}{c}\text { Account manager-related } \\
\text { conditions }\end{array}$} \\
\hline & age & -age & Finlit & -finlit & prtrust & $\sim$ prtrust & integ & -integ & avail & -avail \\
\hline & & & & & & & $\bullet$ & & $\bullet$ & \\
\hline -finlit*integ* ${ }^{*}$ age & & o & & o & & & $\bullet$ & & & \\
\hline$\sim$ finlit $^{*}$ avail ${ }^{*} \sim$ prtrust & & & & o & & o & & & $\bullet$ & \\
\hline integ* ${ }^{*}$ prtrust*age & o & & & & & o & $\bullet$ & & & \\
\hline avail $^{*}$-prtrust ${ }^{*}$-age & & o & & & & $\mathrm{O}$ & & & $\bullet$ & \\
\hline Trust Advanced Relationship & age & -age & finlit & $\sim$ finlit & prtrust & $\sim$ prtrust & integ & -integ & avail & -avail \\
\hline finlit*avail*age & o & & o & & & & & & $\bullet$ & \\
\hline finlit*integ*avail*prtrust & & & o & & o & & o & & $\bullet$ & \\
\hline Trust Basic Relationship & age & -age & finlit & $\sim$ finlit & prtrust & $\sim$ prtrust & integ & -integ & avail & -avail \\
\hline -integ* -avail & & & & & & & & $\bullet$ & & $\bullet$ \\
\hline$\sim$ finlit $^{*} \sim$ integ ${ }^{*} \sim$ prtrust & & & & o & & o & & $\bullet$ & & \\
\hline finlit*-integ*prtrust & & & o & & o & & & $\bullet$ & & \\
\hline -integ ${ }^{*} \sim$ prtrust $^{*}$-age & & o & & & & o & & - & & \\
\hline -finlit*_avail*_age & & o & & o & & & & & & $\bullet$ \\
\hline$\sim$ finlit $^{*} \sim$ avail $^{*} \sim$ prtrust & & & & o & & o & & & & $\bullet$ \\
\hline -avail* prtrust*_age & & o & & & o & & & & & $\bullet$ \\
\hline$\sim$ avail ${ }^{*} \_$prtrust*age & o & & & & & $\mathrm{O}$ & & & & $\bullet$ \\
\hline finlit*avail*prtrust & & & o & & o & & & & & $\bullet$ \\
\hline -Trust Advanced Relationship & age & -age & finlit & $\sim$ finlit & prtrust & $\sim$ prtrust & integ & -integ & avail & -avail \\
\hline -integ*-avail* ${ }^{*}$-prtrust & & & & & o & o & & $\bullet$ & & o \\
\hline -integ* -avail*age & o & & & & & & & $\bullet$ & & o \\
\hline
\end{tabular}

Legend: age = age of the respondent; prtrust = predisposition to trust; avail = availability; compet = competence; integ $=$ integrity; promfful $=$ promise fulfillment; finlit $=$ financial literacy; $\bullet-$ core conditions; $\circ-$ peripheral conditions; $(-)$ absence of the condition.

\section{Conclusion}

Based upon behavioural scales to access investors' perceptions of financial advisors' behaviour and their own predisposition to trust, and on a test to evaluate investors' financial literacy, we were able to test a wide range of conditions. In addition, by testing both trust and absence of trust as possible outcomes, and by using two samples that distinguish investors depending on the degree of their participation in the market (basic or advanced), we were able to carry out an interesting interpretation of the results. On the analytical front, the method used (fsQCA) provides a unique middle ground between qualitative and quantitative methods, being particularly suited for our purposes.

Our overall findings can be summarized as follows.

- Most necessary conditions associated with the trust outcome are related to the way investors perceive the behaviour of the financial advisor. 
- Professional behaviour - in terms of availability, competence, integrity and promise fulfilment - is necessary. Out of these, availability and integrity are critical for basic-type investors. For advancedtype investors, only availability is critical.

- Financial literacy is necessary for both outcomes - trust and no trust - for investors with basic and advanced relationships with the markets. Thus, our results are consistent with the idea of financial literacy being necessary to have an advanced relationship and being more demanding on financial advisors. For investors with a basic relationship, the role of financial literacy is less clear cut, but it would seem that in some scenarios investors with low financial literacy may have no option but to trust their advisors.

- The other investor-related characteristics that play a role, although peripheral, in establishing trust are age and predisposition to trust (or their absence).

- The results for the absence of trust outcome attest the robustness of our trust analysis, also leading to the impression (due to the presence of more configurations leading to the absence of trust outcome, than to trust) that it is easier to achieve the absence of trust than to achieve trust.

This study is important for financial market players, as the results of the research can contribute to a better understanding of the conditions that establish trust between financial advisors and investors who have different degrees of relationship with the market. After reading the results, financial institutions and market players should develop strategies to strengthen the level of confidence in financial markets and improve the relationship between market players and their clients. Institutions need to equip themselves with tools (e.g., assessment courses, counselling, and mentoring) which can help improve financial advisors' behaviour, and metrics which measure their adherence to conditions leading to trust should be included in the performance appraisal system. Banks also need to make a renewed effort to raise the financial literacy of their clients. Both things can cause positive changes in terms of rebuilding investors' trust and increasing their market participation.

This study also proves the usefulness of Butler's psychometric conditions of trust in a different context from usual, i.e., the financial context. Although more studies are needed to confirm the robustness of the conclusions presented here, fsQCA proved to be a useful tool for better understanding the question of trust in the financial market.

It is important to conclude by noting that the nature of the study and the size of the sample do not allow for its conclusions to be generalized, but it opens doors for future research on the matter. It would be interesting to examine in more depth some of the possible biases of our sample. If it is true that some of its characteristics represent limitations to our analysis - e.g. the bias toward young and single respondents - others may in fact be general population characteristics - e.g. mostly employed respondents, and a low percentage of advanced relationships with financial markets. Also, given the option chosen to use questionnaires on a single occasion, it was also not possible to study the effects of the connection over time between investors and financial advisors. It may be that trust changes over time according to the individual's perception of the result delivered by the financial advisor. In this study we did use age, which serves as a proxy for experience (and thus, to some extent, time of connection with financial advisors), but there is room for a deeper future analysis of this matter. In our opinion, the use of interviews would be more efficient in retrieving the information needed to analyse the evolution of the conditions of trust over time.

\section{References}

Agnew, J. R., Szykman, L. R., Utkus, S. P., \& Young, J. A. (2012). Trust, plan knowledge and 401 (k) savings behavior. Journal of Pension Economics \& Finance, 11(1), 1-20. 
Asaad, C. T. (2015). Financial literacy and financial behavior: Assessing knowledge and confidence. Financial Services Review, 24(2), 101-118.

Baptist, C., \& Befani, B. (2015). Qualitative comparative analysis - A rigorous qualitative method for assessing impact, coffey. Retrieved from http://www.coffey.com/assets/Ingenuity/ Qualitative-Comparative-Analysis-June-2015.pdf

Barth, J. R., Caprio Jr, G., \& Levine, R. (2013). Bank regulation and supervision in 180 countries from 1999 to 2011. Journal of Financial Economic Policy, 5(2), 111-219.

Basedau, M., \& Richter T. (2014). Why do some oil exporters experience civil war but others do not?: Investigating the conditional effects of oil. European Political Science Review, 6(4), 549-574.

Bozic, B. (2017). Consumer trust repair: A critical literature review. European Management Journal, 35(4), 538-547.

Butler, J. K., Jr., (1991). Toward understanding and measuring conditions of trust: Evolution of a conditions of trust inventory. Journal of management, 17(3), 643-663.

Calcagno, R., \& Monticone, C. (2015). Financial literacy and the demand for financial advice. Journal of Banking \& Finance, 50, 363-380.

Castle, E., Eisenberger, N. I., Seeman, T. E., Moons, W. G., Boggero, I. A., Grinblatt, M. S., .. \& \& Taylor, S. E. (2012). Neural and behavioral bases of age differences in perceptions of trust. Proceedings of the National Academy of Sciences, 109(51), 20848-20852.

Chortareas, G. E., Garza-García, J. G., \& Girardone, C. (2012). Competition, efficiency and interest rate margins in Latin American banking. International Review of Financial Analysis, 24, 93-103.
Cordell, D. M., Smith, R., \& Terry, A. (2011). Overconfidence in financial planners. Financial Services Review, 20(4), 253-264.

Cruciani, C., \& Rigoni, U. (2017). Trust and financial literacy substitutes or complements?. Quaderni di Finanza CONSOB, (84), 139-43.

Damian, D., \& Manea, C. (2019). Causal recipes for turning fin-tech freelancers into smart entrepreneurs. Journal of Innovation \& Knowledge, 4(3), 196-201.

Dearmon, J., \& Grier, K. (2009). Trust and development. Journal of Economic Behavior \& Organization, 71(2), 210-220.

Delis, M. D., \& Mylonidis, N. (2015). Trust, happiness, and households' financial decisions. Journal of Financial Stability, 20, 82-92.

Dietz, G., \& Den Hartog, D. N. (2006). Measuring trust inside organisations. Personnel Review, 35(5), 557-588.

Ennew, C., \& Sekhon, H. (2007). Measuring trust in financial services: The trust index. Consumer Policy Review, 17(2), 62-68.

Fernández, L. M. V., \& Pinuer, F. J. V. (2016). Influence of customer value orientation, brand value, and business ethics level on organizational performance. RBGN Review of Business Management, 18(59), 5-23.

Ferreira, J. B., Freitas, A. S. D., Nunes, D. C. G., \& Giovannini, C. J. (2014). Factors affecting satisfaction in online financial transactions: a study of Brazilian home brokers. Revista Brasileira de Gestão de Negócios, 16(51), 257-276.

Fiss, P. C. (2007). A set-theoretic approach to organizational configurations. Academy of Management Review, 32(4), 1180-1198.

Fiss, P. C. (2011). Building better causal theories: A fuzzy set approach to typologies in organization 
research. Academy of Management journal, 54(2), 393-420.

Flores, S. A. M., \& Vieira, K. M. (2014). Propensity toward indebtedness: An analysis using behavioral factors. Journal of Behavioral and Experimental Finance, 3, 1-10.

Fukuyama, F. (1995). Trust: The social virtues and the creation of prosperity. (569-598) New York: Free Press.

Garcia-Álvarez-Coque, J-M, Mas-Verdú F. , \& Roig-Tierno, N. (2019). Life below excellence: Exploring the links between top-ranked universities and regional competitiveness. Studies in Higher Education. 1-16. Retrieved from https:// doi.org/10.1080/03075079.2019.1637843

Gennaioli, N., Shleifer, A., \& Vishny, R. (2015). Money doctors. The Journal of Finance, $70(1)$, 91-114.

Georgarakos, D., \& Pasini, G. (2011). Trust, sociability, and stock market participation. Review of Finance, 15(4), 693-725.

Glaser, M., \& Walther, T. (2014, April 16). Run, walk, or buy? Financial literacy, dual-process theory, and investment behavior. Financial Literacy, DualProcess Theory, and Investment Behavior. Retrieved from http://dx.doi.org/10.2139/ssrn.2167270

Greckhamer, T., Misangyi, V. F., Elms, H., \& Lacey, R. (2008). Using qualitative comparative analysis in strategic management research: An examination of combinations of industry, corporate, and business-unit effects. Organizational Research Methods, 11(4), 695-726.

Guiso, L., Sapienza, P., \& Zingales, L. (2004). The role of social capital in financial development. American economic review, 94(3), 526-556.

Guiso, L., Sapienza, P., \& Zingales, L. (2008). Trusting the stock market. the Journal of Finance, 63(6), 2557-2600.
Guiso, L., Sapienza, P., \& Zingales, L. (2009). Cultural biases in economic exchange?. The Quarterly Journal of Economics, 124(3), 10951131.

Kersting, L. M., Marley, R. N., \& Mellon, M. J. (2015). The association between financial literacy and trust in financial markets among novice nonprofessional investors. Academy of Accounting and Financial Studies Journal, 19(3), 201-215.

Kim, G., Shin, B., \& Lee, H. G. (2009). Understanding dynamics between initial trust and usage intentions of mobile banking. Information Systems Journal, 19(3), 283-311.

Kraus, S., Ribeiro, D., \& Schüßler, M. (2018). Fuzzy-set qualitative comparative analysis (fsQCA) in entrepreneurship and innovation research - The rise of a method. International Entrepreneurship \& Management Journal. (14). doi: https://doi.org/10.1007/s11365-017-0461-8

La Porta, R., Lopez-De-Silanes, F., Shleifer, A., \& Vishny, R. W. (1997). Trust in Large Organizations. American Economic Review, 87(2), 333-338.

Lee, K. C., \& Chung, N. (2009). Understanding factors affecting trust in and satisfaction with mobile banking in Korea: A modified DeLone and McLean's model perspective. Interacting with computers, 21(5-6), 385-392.

Lusardi, A., \& Mitchell, O. S. (2007). Baby boomer retirement security: The roles of planning, financial literacy, and housing wealth. Journal of monetary Economics, 54(1), 205-224.

Mannewitz, T. (2011). Two-level theories in QCA: $A$ discussion of Schneider and Wagemann's TwoStep approach [Working Paper 2011, Vol. 64]. Conference: Compasss. Retrieved from http:// www.compasss.org/wpseries/Mannewitz2011.pdf

Mayer, R. C., Davis, J. H., \& Schoorman, F. D. (1995). An integrative model of organizational 
trust. Academy of management review, 20(3), 709-734.

Mayer, C. (2008). Trust in financial markets. European Financial Management, 14(4), 617-632.

Meyer, A. D., Tsui, A. S., \& Hinings, C. R. (1993). Configurational approaches to organizational analysis. Academy of Management Journal, 36(6), 1175-1195.

Nieto-Alemán, P. A., Garcia-Alvarez-Coque, J. M., Roig-Tierno, N., \& Mas-Verdú, F. (2019) Factors of regional poverty reduction in Colombia: Do institutional conditions matter? Social Policy \& Administration, 53(7), 1045-1063.

Nieto Alemán, P. A., Roig-Tierno, N., MasVerdú, F., \& García Álvarez-Coque, J. M. (2018). Multidimensional paths to regional poverty: a Fuzzy-set qualitative comparative analysis of Colombian departments. Journal of Human Development and Capabilities, 19(4), 499-520.

Ott, U. F., Williams, D., Saker, J., \& Staley, L. (2019). A configurational analysis of the termination scenarios of international joint ventures: All is well that ends well. Journal of Innovation \& Knowledge, 4(3), 202-145.

Paliszkiewicz, J. O. (2011). Trust Management: Literature Review. Management, 6(4), 315-333.

Podsakoff, P. M., MacKenzie, S. B., Lee, J. Y., \& Podsakoff, N. P. (2003). Common method biases in behavioral research: A critical review of the literature and recommended remedies. Journal of applied psychology, 88(5), 879-903.

Ragin, C. C. (2000). Fuzzy-set social science. Chicago: University of Chicago Press.

Ragin, C. C. (2009). Redesigning social inquiry: Fuzzy sets and beyond. University of Chicago Press.

Remund, D. L. (2010). Financial literacy explicated: The case for a clearer definition in an increasingly complex economy. Journal of consumer affairs, 44(2), 276-295.

Rezaee, Z. (2005). Causes, consequences, and deterence of financial statement fraud. Critical Perspectives on Accounting, 16(3), 277-298.

Rihoux, B. (2009). Qualitative Comparative Analysis (QCA) and related techniques: Recent advances and challenges. In Methoden der vergleichenden Politik-und Sozialwissenschaft (pp. 365-385). VS Verlag für Sozialwissenschaften.

Rihoux, B., \& Ragin, C. C. (2008). Configurational comparative methods: Qualitative comparative analysis (QCA) and related techniques (Vol. 51). Los Angeles: Sage Publications.

Rooij, M.,van, Lusardi, A., \& Alessie, R. (2011). Financial literacy and stock market participation. Journal of Financial Economics, 101(2), 449-472.

Sapienza, P., \& Zingales, L. (2012). A trust crisis. International Review of Finance, 12(2), 123-131.

Sarigül, H. (2014). A Survey of Financial Literacy Among University Students. Journal of Accounting \& Finance, 64, 207-224.

Schneider, M. R., Schulze-Bentrop, C., \& Paunescu, M. (2010). Mapping the institutional capital of high-tech firms: A fuzzy-set analysis of capitalist variety and export performance. Journal of International Business Studies, 41(2), 246-266.

Schneider, C. Q., \& Wagemann C. (2010). Standards of Good Practice in Qualitative Comparative Analysis (QCA) and Fuzzy-Sets." Comparative Sociology, 9(3), 397-418.

Schneider, C. Q., \& Wagemann, C. (2012). Settheoretic methods for the social sciences: A guide to qualitative comparative analysis. Cambridge: Cambridge University

Simon, M., Houghton, S. M., \& Aquino, K. (2000). Cognitive biases, risk perception, and 
venture formation: How individuals decide to start companies. Journal of business venturing, 15(2), 113-134.

Smithson, M., \& Verkuilen, J. (2006). Fuzzy set theory: Applications in the social sciences. Thousand Oaks : Sage Publications.

Wang, Y. D., \& Emurian, H. H. (2005). An overview of online trust: Concepts, elements, and implications. Computers in human behavior, 21(1), 105-125.

Welter, F. (2012). All you need is trust? A critical review of the trust and entrepreneurship literature. International Small Business Journal, 30(3), 193212.

Williamson, O. E. (1993). Calculativeness, trust, and economic organization. The Journal of Law and Economics, 36(1), 453-486.

Woodside, A. G., \& Zhang, M. (2012). Identifying $\mathrm{x}$-consumers using causal recipes: "Whales" and "jumbo shrimps" casino gamblers. Journal of Gambling Studies, 28(1), 13-26.

Woodside, A. G. (2013). Moving beyond multiple regression analysis to algorithms: Calling for adoption of a paradigm shift from symmetric to asymmetric thinking in data analysis and crafting theory, Journal of Business Research, 66(4), 463472.

Woodside, A. G., Nagy, G., \& Megehee, C. M. (2018). Applying complexity theory: A primer for identifying and modeling firm anomalies. Journal of Innovation \& Knowledge, 3(1), 9-25.

Xu, L., \& Zia, B. (2012). Financial literacy around the world: An overview of the evidence with practical suggestions for the way forward. [Policy Research Working Paper; No. 6107]. World Bank, Washington, DC. (C) World Bank.

Yamagishi, T., \& Sato, K. (1986). Motivational bases of the public goods problem. Journal of Personality and Social Psychology, 50(1), 67-73.

Zadeh, L. A. (1965). Fuzzy sets. Information and control, 8(3), 338-353.

Zadeh, L. A. (1983). The role of fuzzy logic in the management of uncertainty in expert systems. Fuzzy sets and systems, 11(1-3), 199-227.

Zadeh, L. A. (1997). Toward a theory of fuzzy information granulation and its centrality in human reasoning and fuzzy logic. Fuzzy sets and systems, 90(2), 111-127. 


\section{Supporting Agencies:}

Raquel M. Gaspar and Paulo Lopes Henriques gratefully acknowledge the financial support from FCT - Fundação para a Ciencia e Tecnologia (Portugal), and national funding through research grants UIDB/05069/2020 and UIDB/04521/2020, respectively.

\section{Authors:}

1. Raquel M. Gaspar, Ph.D. in Finance, ISEG, Universidade de Lisboa, Lisboa, Portugal.

E-mail: rmgaspar@iseg.ulisboa.pt

\section{ORCID}

(iD) 0000-0003-3294-3962

2. Paulo Lopes Henriques, Ph.D. in Management, ISEG, Universidade de Lisboa, Lisboa, Portugal. E-mail: lopeshen@iseg.ulisboa.pt.

\section{ORCIID}

(iD) 0000-0001-7869-7619

3. Ana Rita Corrente, MSc in Corporate Sciences, ISEG, Universidade de Lisboa, Lisboa, Portugal. E-mail: anaritacorrente@aln.iseg.ulisboa.pt

ORCIID

(iD) 0000-0002-0219-1328

\section{Contribution of each author}

\begin{tabular}{|c|c|c|c|}
\hline Contribution & $\begin{array}{c}\text { Raquel M. } \\
\text { Gaspar }\end{array}$ & $\begin{array}{l}\text { Paulo Lopes } \\
\text { Henriques }\end{array}$ & $\begin{array}{l}\text { Ana Rita } \\
\text { Corrente }\end{array}$ \\
\hline 1. Definition of research problem & $\sqrt{ }$ & $\sqrt{ }$ & $\sqrt{ }$ \\
\hline 2. Development of hypotheses or research questions (empirical studies) & $\sqrt{ }$ & $\sqrt{ }$ & \\
\hline 3. Development of theoretical propositions (theoretical work) & - & - & - \\
\hline 4. Theoretical foundation / Literature review & $\sqrt{ }$ & $\sqrt{ }$ & $\sqrt{ }$ \\
\hline 5. Definition of methodological procedures & & $\sqrt{ }$ & $\sqrt{ }$ \\
\hline 6. Data collection & & & $\sqrt{ }$ \\
\hline 7. Statistical analysis & & $\sqrt{ }$ & $\sqrt{ }$ \\
\hline 8. Analysis and interpretation of data & $\sqrt{ }$ & $\sqrt{ }$ & $\sqrt{ }$ \\
\hline 9. Critical revision of the manuscript & $\sqrt{ }$ & $\sqrt{ }$ & \\
\hline 10. Manuscript writing & $\sqrt{ }$ & $\sqrt{ }$ & \\
\hline 11. Other (please specify which) & - & - & - \\
\hline
\end{tabular}

